UDC 347.952 .3

Submitted: 02.03.2019

LBC 67.410.1

Accepted: 01.04.2019

\title{
CONSISTENCY OF THE PROBLEMATICS OF ENFORCEMENT PROCEEDING FOR SOCIALLY IMPORTANT CASES
}

\author{
Evgeny N. Kuznetsov \\ Ural State Law University, Yekaterinburg, Russian Federation
}

\begin{abstract}
Introduction: the paper deals with the issues of systemic problems of the Russian enforcement proceedings related to the legal, economic, political and social aspects of the state's activity. The high importance of taking into account the economic, political and social sources of the enforcement proceedings problems is determined. It is indicated that the solution of the enforcement problems exclusively in the field of law can't significantly change the state of affairs. The purpose of the study is to propose the main approaches to solving the problems of the enforcement proceedings in the field of economy, politics and social relations. The tasks are the problem statement, the identification of the social significance of the problematics, the analysis of the economic, political and social factors that determine the effectiveness of the Russian enforcement proceedings, and the proposal of ways to solve the problems. The system-logical and formal-legal methods of research are used. Results: the specific measures to improve the Russian enforcement proceedings in the sphere of economy, politics and social relations are proposed, the idea of the need for a comprehensive approach to the reform of the Russian model of enforcement, taking into account all these factors, not only the legal ones, are proposed. Conclusions: especially the lack of effectiveness of the bailiff and executor of justice has a direct impact on the participants of the enforcement proceedings for socially significant cases, which often leads to the failure to achieve the objectives of the mechanism of protection of rights, freedoms and legitimate interests, proclaimed by the Constitution of the Russian Federation. It is important to form a single program to improve the enforcement proceedings in Russia, taking into account all the factors affecting the lack of efficiency of the latter, in their entirety. In the sphere of economy it is necessary to continue further work on strengthening the Russian economy and increase the purchasing power of citizens, and etc. In the field of politics it is possible to consider such areas as the establishment of a balance of interests of the socially unprotected participant of material legal relations and other persons, the increase in the membership of the enforcement proceedings parties, the introduction of special regulations of the enforcement proceedings. In the social sphere it is important to take measures aimed at the formation of respect for the law (social advertising, etc.).

Key words: enforcement proceedings, socially significant cases, bailiff and executor of justice, consistency of problematics, improvement of enforcement proceedings.
\end{abstract}

Citation. Kuznetsov E.N. Consistency of the Problematics of Enforcement Proceeding for Socially Important Cases. Legal Concept, 2019, vol. 18, no. 2, pp. 127-133. (in Russian). DOI: https://doi.org/10.15688/lc.jvolsu.2019.2.21

УДК 347.952 .3

Дата поступления статьи: 02.03.2019

ББК 67.410 .1

Дата принятия статьи: 01.04.2019

\section{СИСТЕМНОСТЬ ПРОБЛЕМАТИКИ ИСПОЛНИТЕЛЬНОГО ПРОИЗВОДСТВА ПО СОЦИАЛЬНО ЗНАЧИМЫМ ДЕЛАМ}

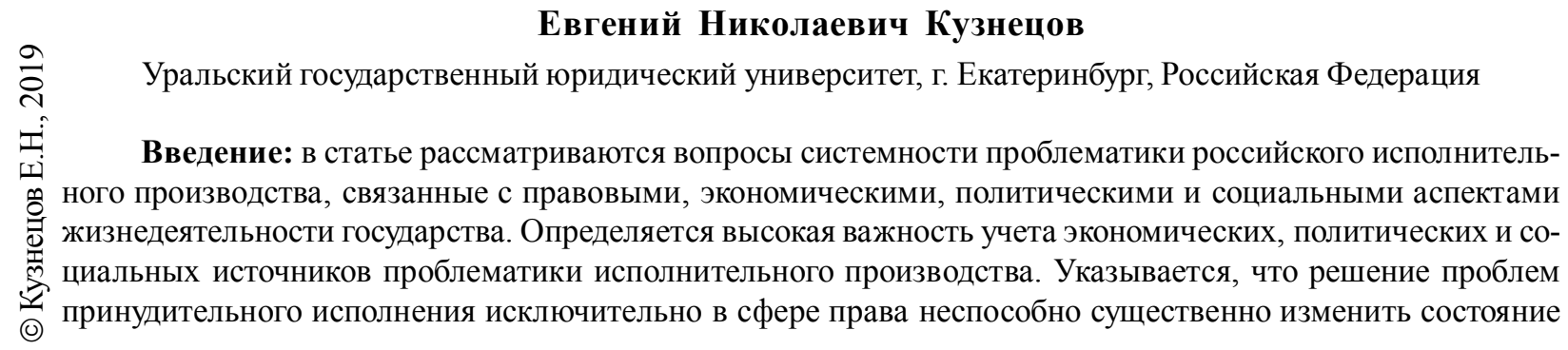


дел. Цель работы - предложить основные подходы к решению проблематики исполнительного производства в сфере экономики, политики и социальных отношений. Задачи: постановка проблемы, выявление ее общественной значимости, анализ экономических, политических и социальных факторов, предопределяющих эффективность российского исполнительного производства, предложение способов решения проблем. В работе использованы системно-логический и формально-юридический методы исследования. Результаты: предложены конкретные меры совершенствования российского исполнительного производства в сфере экономики, политики, социальных отношений, сформулирована идея необходимости комплексного подхода к реформированию российской модели принудительного исполнения с учетом всех указанных факторов, помимо правовых. Выводы: особенно остро недостаточная результативность действий судебного приставаисполнителя непосредственно влияет на участников исполнительного производства по социально значимым делам, что зачастую приводит к недостижению целей механизма защиты прав, свобод и законных интересов, провозглашенного Конституцией Российской Федерации. Важно сформировать единую программу совершенствования исполнительного производства в России, учитывающую все факторы, влияющие на недостаточную эффективность последнего, в их совокупности. В сфере экономики: необходимо дальнейшее продолжение работы по усилению российской экономики, увеличению покупательной способности граждан и др. В сфере политики: возможно рассматривать такие направления, как установление баланса интересов социально-незащищенного участника материальных правоотношений и иных лиц; расширение субъектного состава исполнительных производств; введение специальных регламентов исполнительного производства. В социальной сфере: важно принимать меры, направленные на формирование уважительного отношения к праву (социальная реклама и др.).

Ключевые слова: исполнительное производство, социально значимые дела, судебный пристав-исполнитель, системность проблематики, совершенствование исполнительного производства.

Цитирование. Кузнецов Е. Н. Системность проблематики исполнительного производства по социально значимым делам // Legal Concept = Правовая парадигма. - 2019. - Т. 18, № 2. - C. 127-133. - DOI: https:// doi.org/10.15688/lc.jvolsu.2019.2.21

\section{Введение}

Анализ правовых основ современной регламентации принудительного исполнения в России [2, с. 9-15; 3, с. 8-17; 6, с. 49-51] показывает, что многие проблемы, возникающие в данной сфере, в большей мере носят экономический, политический и социальный характер, чем юридический. Цель настоящей статьи - выявление возможностей повышения эффективности механизма принудительного исполнения путем решения вопросов, связанных с экономической, политической и социальной сферой, прямо или косвенно влияющих на результат действий судебных приставов-исполнителей по социально значимым делам.

\section{Постановка проблемы}

Попытки решения через правовые механизмы проблем конкретной юридической деятельности, не носящих прямо правовой характер, не способны что-либо существенно изменить. Это обусловлено тем, что целевые установки разработки и принятия нормативных правовых актов зачастую не включают в себя иные сферы жизнедеятельности государства. Очевидно, что современное состояние дел в рассматриваемом вопросе характеризуется недостаточной проработкой экономических процессов, происходящих в государстве, отсутствием четкой направленности на решение проблематики исполнительного производства на политическом уровне, опосредованным вниманием к особенностям менталитета, правосознания и иных аспектов социальных отношений [7].

Особенно остро это влияет на сферу социально значимых исполнительных производств, реализуемых в сфере семейных, трудовых, жилищных правоотношений, а также по иные дела, в которых участниками являются лица, относящиеся к социально-незащищенным или уязвимым слоям населения (граждане с низким уровнем доходов, лица пожилого возраста, инвалиды, лица, страдающие психическими заболеваниями, лица, лишенные дееспособности и их опекуны, дети-сироты и их опекуны, дети, оставшиеся без попечения родителей и находящиеся в воспитательных учреждениях, лечебных учреждениях и учреждениях социальной за- 
щиты, нуждающиеся в государственной защите и поддержке в рамках исполнительного производства). Системное решение проблемы повышения эффективности по данным делам должно выступать в настоящее время одним из важнейших аспектов деятельности государства в силу социальной направленности его политики, обусловленной Конституцией РФ (ст. 7).

\section{Экономические факторы, влияющие на эффективность исполнительного производства по социально значимым делам}

К причинам экономического характера, непосредственно связанным с результативностью механизма принудительного исполнения по социально значимым и иным делам, можно отнести следующие:

1) несоразмерность затрат из государственного бюджета на осуществление исполнительных производств по незначительным требованиям;

2) поступление в Федеральную службу судебных приставов фактически реализованных исполнительных документов;

3) трудности в формировании подлинно эффективной системы реализации арестованного имущества;

4) уровень экономического развития ряда регионов страны, препятствующий исполнению судебных постановлений по отдельным категориям дел (например, о предоставлении жилого помещения при отсутствии у субъекта РФ или муниципального образования возможности такое помещение предоставить в сроки, установленные судебным актом);

5) невысокий уровень жизни граждан, препятствующий возможности накопления гражданами имущественной базы, на которую возможно было бы обратить взыскание в ходе принудительного исполнения, и др.

Одним из основных экономических факторов, влияющих на эффективность исполнительного производства, в том числе по социально значимым делам, является низкий уровень покупательной способности граждан, обусловленный невысокими доходами физических лиц в целом по стране. Необходимо дальнейшее продолжение рабо- ты по усилению российской экономики, чтобы в ходе возбуждения исполнительного производства явно прослеживалась экономическая целесообразность применения судебным приставом-исполнителем тех или иных мер, при этом важным выступают активное развитие малого и среднего бизнеca, облегчение условий осуществления деятельности самозанятыми гражданами, послабление налогового режима для отдельных категорий предпринимателей (малый бизнес) и другие меры.

В отдельных международных актах (см., например: [4]) прямо указывается, что исполнительное производство реализуется только в тех случаях, когда должник может и способен выполнить требования исполнительного документа. Если должник неплатежеспособен, то инициирование судебных процедур в целях взыскания долга и исполнительного производства свидетельствует об изначальной бесцельности соответствующего вида государственной деятельности. В данной связи важно искать новые способы решения проблем неплатежеспособности должника. Например, оказывать содействие в его трудоустройстве, контролировать выполнение им трудовых функций под угрозой применения административной или уголовной ответственности, для чего важно разработать новые правовые регламенты соответствующих аспектов жизнедеятельности должника, и т. д.

Важно делать здесь акцент на повышении экономических гарантий жизнедеятельности граждан, относящихся к социально-незащищенным категориям лиц, и их социальной защиты. Это обусловлено повышенными социальными обязательствами государства к тем гражданам, которые испытывают трудности в правовой защите.

Совершенствование исполнительного производства должно учитывать экономические факторы, поскольку право и экономика не находятся в связи соподчинения, они должны взаимно дополнять и поддерживать друг друга. Между тем одного учета этого обстоятельства недостаточно, поскольку важным является понимание воздействия на происходящие процессы политических и социальных процессов. 


\section{Политические факторы, влияющие на эффективность \\ исполнительного производства \\ по социально значимым делам}

Ряд причин недостаточной эффективности исполнительного производства обусловлен сферой политики. К ним можно отнести следующие:

1) отсутствие комплексного подхода к пониманию необходимости системного разрешения проблем исполнительного производства с точки зрения права, экономики и социальных отношений;

2) длительность законотворческих процессов по совершенствованию законодательства об исполнительном производстве (затянувшаяся работа по разработке и принятию Исполнительного Кодекса РФ);

3) отсутствие законодательных инициатив по постепенному переходу к небюджетной модели принудительного исполнения.

Политическая воля должна быть направлена на постоянную поддержку научных изысканий и практических способов устранения конкретных проблем механизма принудительного исполнения, поскольку только такой подход способен изменить текущую ситуацию. Без этого содействия исполнительное производство будет тормозить экономический рост государства и вызывать критику со стороны мирового сообщества в правовой сфере по причине неспособности органов государственной власти оптимальным образом решить проблему правовой защиты граждан и организаций.

С учетом особой социальной значимости ряда исполнительных производств (по трудовым, семейным, жилищным и другим делам, участниками которых являются социально-незащищенные категории граждан) важным становится проявление политической воли в отношении совершенствования механизмов принудительного исполнения. Так, целесообразно установление баланса интересов социально-незащищенного участника материальных правоотношений и иных лиц, задействованных в конкретной ситуации; расширение субъектного состава соответствующих исполнительных производств (привлечение педагогов по делам с участием несовершеннолет- них лиц, представителей Гострудинспекции по трудовым спорам, жилищных инспекций по жилищным делам и др.); введение специальных регламентов исполнительного производства (ускоренное применение мер принудительного исполнения и косвенного побуждения должника к исполнению обязанностей по семейным и трудовым делам, введение обязательной медиации по жилищным спорам и др.). После апробации соответствующих мер на социально значимых исполнительных производствах возможно их расширение на все остальные категории дел, находящихся в производстве судебных приставов-исполнителей.

\section{Социальные факторы, влияющие на эффективность исполнительного производства по социально значимым делам}

Не следует недооценивать важность социальных факторов в механизме совершенствования исполнительного производства, поскольку на оптимальное функционирование механизма правозащитной деятельности оказывает существенное влияние отношение общества и отдельных граждан к соответствующей сфере деятельности. К сожалению, в Российской Федерации данные факторы приобретают колоссальное влияние, существенным образом влияя на недостаточную эффективность исполнительного производства.

Зачастую складываются ситуации, когда гражданин понимает, что вынесенное против него судебное решение или акт иного юрисдикционного органа может быть не исполнен в силу причин объективного или субъективного порядка, поэтому он не считает должным прилагать усилий к добровольному исполнению обязательства, а к процедурам принудительного исполнения относится с пренебрежительным снисхождением. Причинами этого являются воспитание, уровень жизни, окружение человека, внешний фон представлений о деятельности Федеральной службы судебных приставов как чего-то негативного, чего следует избегать, внутренняя конфронтация личности с установками государственно-властного характера, нежелание исполнять «навязанные свыше» или «извне» порядки, противопоставление условиям исполнения соб- 
ственных обязательств недовольство действиями чиновников различного уровня, подогреваемое информационным фоном о коррупционности представителей власти и др.

К социальным факторам, влияющим на проблемы развития исполнительного производства по социально значимым делам, можно отнести следующие:

1) высокий уровень правового нигилизма в российском обществе, недостаточный уровень уважения к государственным институтам, требованиям законов и необходимости соблюдения прав, свобод и законных интересов других лиц;

2) недостаточная работа со стороны государственных и общественных институтов на преодоление существующих установок о возможности неисполнения установленных правил поведения;

3) существующие в обществе установки на возможность и допустимость противоправного поведения, на высокий уровень безнаказанности за совершение тех или иных проступков или нарушений прав, свобод и законных интересов других лиц, на игнорирование требований о беспрекословном исполнении судебных актов;

4) возникающие возможности для коррупционного поведения в сфере государственного управления, в том числе и принудительного исполнения;

5) терпимость граждан к коррупционным действиям со стороны представителей органов государственной власти с одновременным осуждением такого поведения и низким уровнем доверия к государству, закону и праву;

6) существующие возможности коммерциализации деятельности судебных приставовисполнителей, что крайне негативно влияет на восприятие ФССП со стороны конкретных участников исполнительного производства и общества в целом;

7) восприятие сторонами исполнительного производства вынесенного судебного акта, являющегося объективно неисполнимым, как нелегитимного, что, в свою очередь, подрывает доверие к органам как принудительного исполнения, так и судебной власти;

8) неуважение к Федеральной службе судебных приставов, нежелание молодых специалистов - выпускников юридических вузов заниматься данным видом деятельности либо рассмотрение службы в ФССП как стартовой площадки для получения опыта в целях дальнейшего трудоустройства в коммерческие банки и иные кредитные организации, а также в коллекторские агентства, либо для нарабатывания «нужных» связей.

\section{Способы усиления эффективности исполнительного производства}

Основными способами преодоления такой ситуации могут выступать, помимо указанных выше, следующие:

1. Создание таких условий деятельности судебного исполнителя, при которых он имеет высокий уровень дохода, материальнотехнического оснащения, а также уважительное отношение со стороны как граждан, так и иных представителей юридического сообщества. По данной причине необходимо пересмотреть систему оплаты труда судебных приставов-исполнителей. При отсутствии для этого ресурсов в бюджетной системе Российской Федерации - рассматривать возможности перевода судебных приставов-исполнителей на самофинансирование при установлении очень жестких рамок совершения соответствующих действий, восстановить систему возврата судебным приставам-исполнителям части взысканного исполнительского сбора.

Повышение мотивации будет способно снизить коррупционную составляющую в деятельности должностных лиц системы органов принудительного исполнения, исключит коммерциализацию деятельности судебного пристава-исполнителя. Это также позволит решить вопросы повышения статуса, престижа Федеральной службы судебных приставов, что, в свою очередь, прямо влияет на повышение уровня правосознания граждан, снижения уровня правового нигилизма. При этом важно установить критерии эффективности конкретного подразделения службы или судебного пристава-исполнителя в зависимости от реальной исполнимости ряда исполнительных производств (по делам неимущественного характера, малозначительных требований, алиментным обязательствам).

2. Формирование модели добровольности исполнения требований исполнительных до- 
кументов, которая будет способна повлиять в какой-то части на решение проблемы правового нигилизма.

Для этого важно вести просветительскую правовую работу, транслировать социальную рекламу, совершать иные действия, направленные на формирование неблагоприятного образа должника, не исполняющего свои обязанности в добровольном порядке, одновременно внедряя в сознание граждан важность и целесообразность добровольности исполнения различных исполнительных документов, повышая уровень уважения к праву и снижая тем самым уровень правового скептицизма.

Эффективным является распространение информации о должнике в широком формате, в круге его общения, в том числе в интернет-ресурсах (социальных сетях), что, безусловно, потребует изменения законодательства о защите персональных данных, но вынудит многих должников самостоятельно предпринимать меры по погашению просроченной задолженности и не допускать подобных ситуаций впредь.

\section{Выводы}

Попытки решения проблем, возникающих в российском исполнительном производстве, исключительно через реформирование правовой системы $[1$, с. $134-141 ; 5$, с. 149 155] не способны привести к системному повышению эффективности российского исполнительного производства, поскольку источником многих сложностей выступают экономические, политические и социальные факторы. При этом особенно остро недостаточная результативность действий судебного приставаисполнителя непосредственно влияет на участников исполнительного производства по социально значимым делам, зачастую приводит к недостижению целей механизма защиты прав, свобод и законных интересов, провозглашенного Конституцией Российской Федерации. В данной связи представляется важным формирование единой программы совершенствования исполнительного производства в России, учитывающей все факторы, влияющие на недостаточную эффективность последнего, в их совокупности.

\section{СПИСОК ЛИТЕРАТУРЫ}

1. Валеев, Д. Х. Концепция развития законодательства об исполнительном производстве Российской Федерации / Д. Х. Валеев // Принудительное исполнение актов судов и иных органов. Полномочия должностных лиц при осуществлении исполнительных действий : сб. материалов Международ. науч.практ. конф., 6-8 июля 2010 г., г. Санкт-Петербург / отв. ред. А. О. Парфенчиков, Н. М. Кропачев, Д. Х. Валеев. - М. : Статут, 2013. - С. 134-142.

2. Парфенчиков, А. О. Проблемы развития и совершенствования системы принудительного исполнения судебных актов и актов иных органов в Российской Федерации / А. О. Парфенчиков // Эффективность принудительного исполнения судебных решений и актов иных органов : сб. материалов Междунар. науч.-практ. конф., г. Казань, 811 июня 2011 г. / отв. ред. А. О. Парфенчиков, Д. Х. Валеев. - М. : Статут, 2011.- С. 9-15.

3. Парфенчиков, А. О. Проблемные аспекты принудительного исполнения актов судов и иных органов в отношении юридических лиц в Российской Федерации / А. О. Парфенчиков // Принудительное исполнение актов судов и иных органов в отношении юридических лиц (организаций и предпринимателей) : сб. материалов Междунар. науч.практ. конф., 4-8 июня 2012 г., г. Воронеж / отв. ред. А. О. Парфенчиков, Д. Х. Валеев. - М. : Статут, 2013. - C. 8-17.

4. Проект Долгосрочной программы повышения эффективности исполнения судебных решений (2011-2020 годы). - Электрон. текстовые дан. Режим доступа: http://docs.pravo.ru/document/view/ 10963602 (дата обращения: 19.03.2019).

5. Рассахатская, Н. А. Тенденции развития исполнительного производства / Н. А. Рассахатская // Принудительное исполнение актов судов и иных органов. Полномочия должностных лиц при осуществлении исполнительных действий : сб. материалов Междунар. науч.-практ. конф., 6-8 июля 2010 г., г. Санкт-Петербург / отв. ред. А. О. Парфенчиков, Н. М. Кропачев, Д. Х. Валеев. - М. : Статут, 2013. - С. 149-155.

6. Ярков, В. В. К вопросу о современном состоянии российского исполнительного производства по социально значимым делам / В. В. Ярков, Е. Н. Кузнецов // Арбитражный и гражданский процесc. - 2017. - № 11. - С. 49-51.

7. Lignes Directrices Pour une Meilleure Mise en Oeuvre de La Recommandation Existante du Conseil de L'europe sur L'execution // Commission Europeenn e Pour L'efficacite de La Justice (CEPEJ). - Electronic text data. - Mode of access: http://www.uihj.com/ ressources/21628/67/lignes_directrices_de_la_cepej_ sur_1_execution.pdf(Accessed: 19 March 2019). 


\section{REFERENCES}

1. Valeev D.Kh. Concept of Developing Legislation on Enforcement Proceedings of the Russian Federation. A.O. Parfenchikov, N.M. Kropachev, D.Kh. Valeev, eds. Enforcement of Acts of Courts and Other Bodies. Powers of Officers While Exercising Executive Actions: Proceedings of the International Scientific-Practical Conference, 68 July 2010, Saint Petersburg. Moscow, Statut Publ., 2013, pp. 134-142. (in Russian).

2. Parfenchikov A.O. Problems of Developing and Improving the System of Compulsory Enforcement of Acts of Courts and Other Bodies in the Russian Federation. Parfenchikov A.O., Valeev D.Kh., eds. Efficiency of Enforcement of Judicial Decisions and Acts of Other Bodies: Proceedings of the International Scientific-Practical Conference, Kazan, 8-11 June 2011. Moscow, Statut Publ., 2011, pp. 9-15. (in Russian).

3. Parfenchikov A.O. Problematic Aspects of Compulsory Enforcement of Acts of Courts and Other Bodies in Relation to Legal Entities in the Russian Federation. Parfenchikov A.O., Valeev D.Kh., eds. Compulsory Enforcement of Acts of Courts and Other Bodies in Relation to Legal Entities (Organizations and Entrepreneurs): Proceedings of the International
Scientific-Practical Conference, 4-8 July 2012, Voronezh. Moscow, Statut Publ., 2013, pp. 8-17. (in Russian).

4. Draft Long-Term Programme of Improving the Efficiency of Court Decision Enforcement (20112020). URL: http://docs.pravo.ru/document/view/ 10963602 (accessed 19 March 2019). (in Russian).

5. Rassakhatskaya N.A. Trends in the Development of Executive Production. Parfenchikov A.O., Kropachev N.M., Valeev D.Kh., eds. Enforcement of Acts of Courts and Other Bodies. Powers of Officers While Exercising Executive Actions: Proceedings of the International Scientific-Practical Conference, 6-8 July 2010, Saint Petersburg. Moscow, Statut Publ., 2013, pp. 149-155. (in Russian).

6. Yarkov V.V., Kuznetsov E.N. To the Issue of the Current State of the Russian Enforcement Proceedings on Socially Significant Cases. Arbitrazh and Civil Procedure, 2017, no. 11,pp. 49-51. (in Russian).

7. Lignes Directrices Pour une Meilleure Mise en Oeuvre de La Recommandation Existante du Conseil de L'europe sur L'execution. Commission Europeenn e Pour L'efficacite de La Justice (CEPEJ). URL: http://www.uihj.com/ressources/ 21628/67/lignes_directrices_de_la_cepej_sur _1_execution.pdf (accessed 19 March 2019). (in French).

\section{Information about the Author}

Evgeny N. Kuznetsov, Candidate of Sciences (Jurisprudence), Associate Professor, Department of Civil Procedure, Ural State Law University, Komsomolskaya St., 21, 620137 Yekaterinburg, Russian Federation, Corben2002@mail.ru, https://orcid.org/0000-0001-7787-0328

\section{Информация об авторе}

Евгений Николаевич Кузнецов, кандидат юридических наук, доцент кафедры гражданского процесса, Уральский государственный юридический университет, ул. Комсомольская, 21, 620137 г. Екатеринбург, Российская Федерация, Corben2002@mail.ru, https://orcid.org/0000-0001$7787-0328$ 